\title{
Whatever? The effect of social exclusion on adopting persuasive messages
}

\author{
Michaela Pfundmair ${ }^{\mathrm{a}}$, Nilüfer Aydin ${ }^{\mathrm{b}}$, and Dieter Frey ${ }^{\mathrm{a}}$ \\ aLudwig-Maximilians University of Munich; ${ }^{\text {b} A l p e n-A d r i a ~ U n i v e r s i t y ~ o f ~ K l a g e n f u r t ~}$
}

\begin{abstract}
The aversive state of social exclusion can result in a broad range of cognitive deficits. Being unable or unmotivated to process relevant information, we assumed that social exclusion would also affect the success of persuasive attempts. We hypothesized that socially excluded people would adopt attitudes regardless of persuasion quality. In three studies using different manipulations of social exclusion and persuasion, we showed that participants who were socially excluded adopted persuasive messages regardless of argument quality. In contrast, this undifferentiated response was not shown by socially included participants who were more persuaded by high- compared to low-quality arguments. In Study 3, we moreover revealed that this pattern could only be replicated in reliable situationsthat is, when the communicator appeared credible. These findings support the assumption that social exclusion can lead to reduced processing of information.
\end{abstract}

\section{ARTICLE HISTORY}

Received 6 August 2015

Accepted 13 April 2016

\section{KEYWORDS}

Cognition; persuasion; social exclusion

People have a fundamental need to belong (Baumeister \& Leary, 1995), and threatening this need can result in severe consequences: Socially excluded individuals not only face a decrease of their basic needs belonging, self-esteem, control, and meaningful existence (see Williams, 2009) but are also confronted with feelings similar to physical pain (Eisenberger, Lieberman, \& Williams, 2003). Social exclusion also has negative consequences on a cognitive level: It can decrease performance on intelligence tests (Baumeister, Twenge, \& Nuss, 2002), distort time perception (Twenge, Catanese, \& Baumeister, 2003), and impair self-regulation (Baumeister, DeWall, Ciarocco, \& Twenge, 2005). Socially excluded people, however, do not necessarily become unable but rather unwilling to selfregulate: Under specific circumstances (e.g., given a compelling incentive), they can put forth the effort that self-regulation requires (Baumeister et al., 2005). Cognitive deficits, as usually observed after social exclusion, are often followed by low-level processing and, as a result, affect the success of persuasive messages. Impaired self-regulation, for example, has been shown to increase the odds of compliance with requests (Janssen, Fennis, Pruyn, \& Vohs, 2008). The current research aimed to investigate how the state of social exclusion influences the success of persuasive attempts.

People often aim to resist persuasion in order to hold correct attitudes, restore freedom, or sustain psychological consistency and control (Wegener, Petty, Smoak, \& Fabrigar, 2004). However, this resistance can be influenced by a variety of factors-for example, the importance of the respective attitude (Zuwerink \& Devine, 1996). In the case of social exclusion, it has been proposed that if a persuasive attempt offers an opportunity to form social bonds with others, socially excluded people are more likely to be influenced by such an attempt (Williams, Chen, \& Wegener, 2010). This has also been validated empirically: Socially excluded people have been shown to adopt attitudes from potential affiliates (DeWall, 2010), comply with persuasive attempts from others (Carter-Sowell, 
Chen, \& Williams, 2008), and follow requests that require conformity (Williams, Cheung, \& Choi, 2000) and obedience (Riva, Williams, Torstrick, \& Montali, 2014). Although it has been argued that socially excluded people are more persuaded by appeals that provide chances to improve social connections (Williams et al., 2010), people's susceptibility to persuasive attempts in response to social exclusion has been revealed to be rather undifferentiated: Excluded people became persuaded both by a technique called "door-in-the-face" and by a technique called "foot-in-the-door" (CarterSowell et al., 2008), although only the "door-in-the-face" technique operated under an implied social contract of reciprocity (Cialdini et al., 1975). Therefore, it might be argued that it is not necessarily the social cue that makes excluded people more open to adopt persuasive messages. Cognitive deficits following exclusion might also lead people to accept information in an undifferentiated manner.

This reasoning is in line with predictions of the elaboration likelihood model of persuasion: Although people want to hold correct attitudes, the amount of effort they are able or willing to engage in varies. The ELM postulates that only people who are motivated and able to seek the truth can process all relevant information (Petty, 2013; Petty \& Cacioppo, 1981). Under distraction or cognitive load, however, the processing of persuasive messages is reduced (Petty, Wells, \& Brock, 1976). Thus, when the likelihood of elaboration is low, only few cognitive resources will be allocated to the advocacy. Accordingly, when self-regulatory resources are depleted, people have been shown to be more likely to "give in" (Baumeister \& Heatherton, 1996). Under such conditions of reduced processing, people usually employ shortcuts to arrive at decisions. People in reduced elaboration settings are, for example, often influenced by the heuristic that claims of a credible communicator are valid (Chaiken \& Maheswaran, 1994). Consistently, a low level of self-regulatory resources has been shown to foster compliance with an influence agent because he or she is a credible source (Janssen et al., 2008).

Based on these considerations, we suggest that the cognitive decrements after social exclusion (e.g., Baumeister et al., 2005; Baumeister et al., 2002; Twenge et al., 2003) might reduce people's willingness to scrutinize all available information. As a consequence, excluded people might not necessarily have a generally lower resistance against persuasion but rather tend to adopt persuasive messages regardless of content, in particular when a situation is reliable due to factors like source credibility. Thus, we hypothesized that, under reliable conditions, excluded people would be persuaded regardless of argument quality, whereas included people would be more persuaded by qualitatively high compared to qualitatively low arguments.

\section{Overview}

We investigated this hypothesis using three different manipulations of social exclusion: a life-alone task (Study 1), a scenario task (Study 2), and an essay task (Study 3). We moreover implemented three different manipulations of persuasion quality: a product ad (Study 1), a job candidate's vita (Study 2), and a proposal for implementing a sustainability label (Study 3). In each study, we measured the persuasive success. In Study 3, we moreover explored a boundary condition regarding the susceptibility to persuasion by manipulating source credibility.

\section{Study 1}

Study 1 was a first test to determine how social exclusion influences the success of a persuasive attempt. We manipulated inclusionary status using a future-alone or future-belonging feedback (Twenge, Baumeister, Tice, \& Stucke, 2001) and persuasion quality using a product ad with lowand high-quality arguments (Kerr, Beede, Proud, \& Schultz, 2010; Petty, Cacioppo, \& Schumann, 1983). We predicted that excluded participants would adopt persuasive information regardless of argument quality, whereas included participants would be more persuaded by high compared to low argument quality. 


\section{Method}

\section{Participants and design}

One-hundred-and-thirty-six students from a German university participated in this online study and received research credit for volunteering. As we could not control for background conditions, we excluded participants who needed $1 S D \pm$ of the average duration to complete the experiment ( $M=19.81 \mathrm{~min}, S D=13.42$; according to previous research (Pfundmair, Lermer, Frey, \& Aydin, 2015 ) in order to ensure sufficient impact of our manipulations. The final sample consisted of 114 participants (94 female, 19 male, and 1 who did not specify sex; age: $M=23.22, S D=7.56$ ).

The experiment was based on a 2 (inclusionary status: exclusion vs. inclusion) $\times 2$ (persuasion quality: low vs. high) between-subject design with random assignment to conditions.

\section{Procedure and materials}

After indicating their consent, participants read the cover story. The cover story informed participants that the study was conducted for the department of advertising psychology and investigated the relationship between personality and purchasing decisions. Participants first underwent an exclusion vs. inclusion manipulation based on Twenge et al. (2001). They were asked to fill out a personality questionnaire including 12 items of an extraversion scale and 12 items of an agreeableness scale (Costa \& McCrae, 1992), as well as six additional items about the future to bolster the cover story. After that, false feedback on the personality test followed: In order to gain credibility, the computer first gave an accurate assessment of the participant's real extraversion score presenting a "personality type" description. Participants in the future-alone condition (exclusion condition) were then told that they would end up alone later in life. Participants in the future-belonging condition (inclusion condition) were told that they would have rewarding relationships throughout life. After that, they filled out a manipulation check. Based on procedures by Petty et al. (1983; modernized by Kerr et al., 2010), participants were subsequently presented a bogus ad for a disposable razor, the Edge. They were instructed to read through the ad that contained either weak (low-quality condition) arguments (e.g., "Designed by a team of experts") or strong (high-quality condition) arguments (e.g., "Designed with the performance of a premium razor plus the convenience, hygiene and value of a disposable"). Then, they filled out an item on purchasing intentions and another manipulation check. Upon completion, participants were thoroughly debriefed.

\section{Manipulation check (inclusionary status)}

Participants completed the following question: "I feel that other people will interact with me in the future a lot" on a $1=$ not at all to $5=$ very much response scale.

\section{Purchasing intention}

As in Petty et al. (1983) and Kerr et al. (2010), participants were asked to rate how likely it would be that they would purchase an Edge disposable razor on a $1=I$ definitely would not buy it to $4=I$ would definitely buy it response scale.

\section{Manipulation check (persuasion quality)}

Participants answered the following question: "How convincing did you experience the arguments to purchase the product?" on a $1=$ not very convincing to $9=$ very convincing response scale.

\section{Results}

\section{Manipulation checks}

To check the impact of the inclusionary status manipulation, a t-test was conducted on the manipulation check of inclusionary status (as this manipulation check came before the persuasion 
quality manipulation, persuasion quality was not included as a factor in this analysis). Participants in the exclusion condition reported marginally significantly less often that other people would interact with them in the future $(M=3.75, S D=0.63)$ than participants in the inclusion condition $(M=3.98$, $S D=0.76), t(112)=1.81, p=.073, d=0.34,95 \% \mathrm{CI}=[-0.03,0.71]$. To check the impact of the persuasion quality manipulation, we further conducted at 2 (inclusionary status) $\times 2$ (persuasion quality) ANOVA on the manipulation check of persuasion quality. Neither the main effect of inclusionary status, $F(1,109)=0.21, p=.648$, nor the interaction, $F(1,109)=0.45, p=.503$, revealed significance; however, a significant main effect of persuasion quality emerged, $F(1,109)=18.16$, $p<.001, \eta^{2}=.14,95 \% \mathrm{CI}=[0.04,0.26]$. Participants in the low-quality condition experienced the arguments as significantly less convincing $(M=3.37, S D=1.90)$ than participants in the high-quality condition $(M=4.94, S D=2.02)$.

\section{Purchasing intention}

The 2 (inclusionary status) $\times 2$ (persuasion quality) ANOVA on purchasing intention revealed no main effect of inclusionary status, $F(1,109)=0.04, p=.839$, but a significant main effect of persuasion quality emerged, $F(1,109)=9.00, p=.003, \eta^{2}=.08,95 \% \mathrm{CI}=[0.01,0.18]$. Participants in the low-quality condition expressed a significantly lower purchasing intention $(M=2.06$, $S D=0.74)$ than participants in the high-quality condition $(M=2.47, S D=0.70)$. Moreover, the ANOVA showed a marginally significant interaction effect, $F(1,109)=3.05, p=.084, \eta^{2}=.03,95 \%$ $\mathrm{CI}=[0.00,0.11]$. Simple main effect analyses revealed that participants in the inclusion condition indicated significantly higher purchasing intentions when the razor was presented with high-quality arguments $(M=2.59, S D=0.67)$ compared to low-quality arguments $(M=1.94, S D=0.70), F$ $(1,109)=10.76, p=.001, \eta^{2}=.09,95 \% \mathrm{CI}=[0.01,0.20]$. Participants in the exclusion condition, on the other hand, did not differ in their purchasing intention when faced with high- $(M=2.38$, $S D=0.73)$ or low-quality arguments $(M=2.21, S D=0.77), F(1,109)=0.83, p=.365$, see Figure 1 .

\section{Discussion}

Whereas included participants indicated higher purchasing intentions when high-quality arguments were presented than when low-quality arguments were presented, excluded participants expressed similar purchasing intentions regardless of argument quality. This undifferentiated behavior might reflect the participants' inability to process all relevant information (Petty,

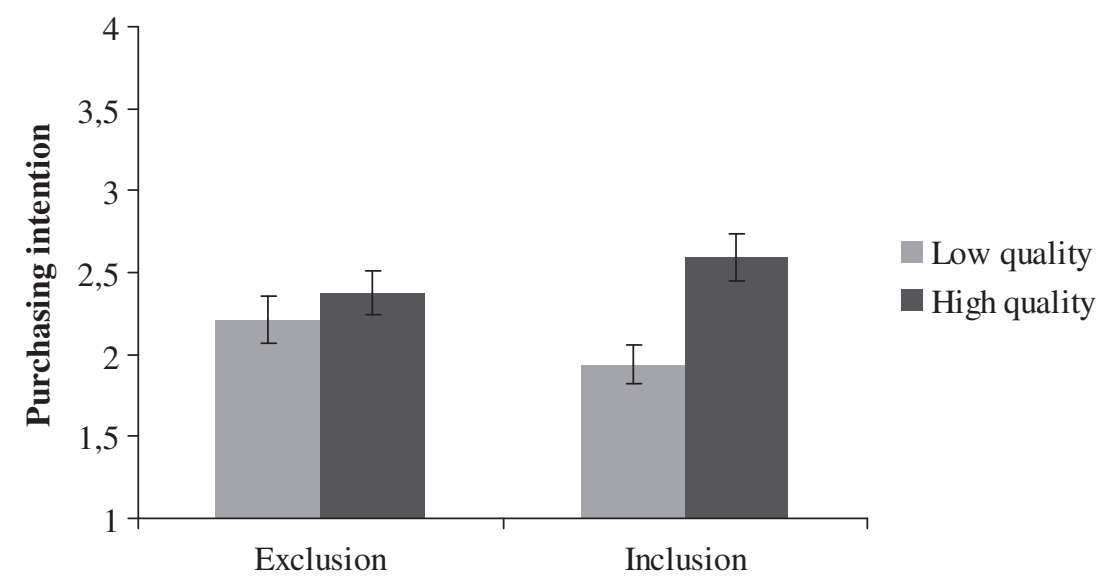

Figure 1. The effect of inclusionary status $\times$ persuasion quality on purchasing intention (Study 1); error bars represent \pm 1 SE. 
2013; Petty \& Cacioppo, 1981) and underlines the cognitive deficits following social exclusion as observed in previous research (Baumeister et al., 2005; Baumeister et al., 2002; Twenge et al., 2003). However, it should be noted that this effect was based on only marginal significance levels. This might have been caused by our exclusion manipulation, the life-alone paradigm: In contrast to other manipulations, life-alone often results in relatively flat affective states (Bernstein \& Claypool, 2012a). This is related to the assumption that this paradigm is a more severe form of social exclusion leading to qualitatively different, namely numbing, outcomes (Bernstein \& Claypool, 2012b). This flat affective state that has been mirrored in our manipulation check might have resulted in the small persuasion effect. Therefore, in the next study, we aimed to investigate our hypothesis using a different design.

\section{Study 2}

The first study indicated that social exclusion makes people adopt persuasive messages regardless of content. In the second study, we aimed to replicate these findings using different manipulations. We manipulated inclusionary status using a scenario task (Aydin, Fischer, \& Frey, 2010) and persuasion quality using a job candidate's vita that was either strong or weak (Briñol, Petty, \& Stavraki, 2012). We hypothesized again that excluded participants would be persuaded regardless of argument quality, whereas included participants would be more persuaded by arguments with high compared to low quality.

\section{Method}

\section{Participants and design}

In this online study, 120 students and university co-workers volunteered for research credit. As in Study 1, we excluded participants who needed $1 S D \pm$ of the average duration to complete the experiment $(M=14.43 \mathrm{~min}, S D=9.31)$. The final sample consisted of 106 participants ( 81 female, 23 male, and 2 who did not specify sex; age: $M=27.95, S D=9.42$ ).

Again, the experiment was based on a 2 (inclusionary status: exclusion vs. inclusion) $\times 2$ (persuasion quality: low vs. high) between-subject design with random assignment to conditions.

\section{Procedure and materials}

After indicating their consent, participants read the cover story that informed them that the study would investigate experiences and attitudes in the employment context. First, participants were asked to carefully read a scenario and try to put themselves into the position of the individual in the story that has been shown to induce reactions comparable to those using interpersonal methods for creating exclusion (Fiske \& Yamamoto, 2005; Hitlan, Kelly, Shepman, Schneider, \& Zaraté, 2006). The following procedure was based on Aydin et al. (2010). Participants either read a story in which they were told that their colleagues refused contact with them, and their boss excluded and ignored them (exclusion condition). Or participants read a story in which they were asked to imagine that they were highly accepted by their colleagues and boss (inclusion condition). After that, they completed a manipulation check. Based on Briñol et al. (2012), participants then viewed a vita for a job candidate applying for a position as deputy marketing director. They were asked to carefully read the vita containing either weak (low-quality condition) merits (e.g., candidate has yet to get some of this degrees, has experience in unrelated jobs) or strong (high-quality condition) merits (e.g., candidate has degrees from a prestigious university, has professional experience in well-known corporations). Subsequently, participants were asked about their hiring intentions and filled out another manipulation check. This was followed by a debriefing. 


\section{Manipulation check (inclusionary status)}

Participants were asked to respond to statements imagining themselves in the scenario. On $1=$ not at all to $7=$ very much response scales, they responded to 20 items measuring belonging (e.g., "I feel 'disconnected"), self-esteem (e.g., "I feel good about myself"), control (e.g., "I feel powerful"), and meaningful existence (e.g., "I feel invisible"), which were combined to an overall need-fulfilment scale ( $\alpha=.98$; based on Jamieson, Harkins, \& Williams, 2010).

\section{Hiring intention}

Participants were asked to rate how likely it would be that they would hire the job candidate on a $1=I$ definitely would not hire him to $4=I$ would definitely hire him response scale.

\section{Manipulation check (persuasion quality)}

Participants answered the following question: "How convincing did you experience the job candidate's vita?" on a $1=$ not very convincing to $9=$ very convincing response scale.

\section{Results}

\section{Manipulation checks}

To check the impact of the inclusionary status manipulation, a t-test was conducted on the manipulation check of inclusionary status. Excluded participants reported significantly less need fulfilment $(M=2.31, S D=0.69)$ than included participants $(M=5.87, S D=0.54), t(104)=29.21$, $p<.001, d=5.68,95 \% \mathrm{CI}=[4.80,6.54]$. To check the impact of the persuasion-quality manipulation, we conducted at 2 (inclusionary status) $\times 2$ (persuasion quality) ANOVA on the manipulation check of persuasion quality. Neither the main effect of inclusionary status, $F(1,102)=0.15, p=.700$, nor the interaction, $F(1,102)=0.46, p=.501$, revealed significance; however, a significant main effect of persuasion quality emerged, $F(1,102)=19.33, p<.001, \eta^{2}=.16,95 \% \mathrm{CI}=[0.05,0.28]$. Participants in the low-quality condition experienced the vita as significantly less convincing $(M=3.92, S D=1.81)$ than participants in the high-quality condition $(M=5.58, S D=1.99)$.

\section{Hiring intention}

A 2 (inclusionary status) $\times 2$ (persuasion quality) ANOVA on the hiring intention showed no main effect of inclusionary status, $F(1,102)=0.03, p=.869$, but a significant main effect of persuasion quality emerged, $F(1,102)=14.99, p<.001, \eta^{2}=.13,95 \% \mathrm{CI}=[0.03,0.25]$. Participants viewing a weak vita expressed a significantly lower hiring intention $(M=2.43, S D=0.61)$ than participants viewing a strong vita $(M=2.88, S D=0.60)$. Moreover, the ANOVA indicated a significant interaction, $F(1,102)=4.12, p=.045, \eta^{2}=.04,95 \% \mathrm{CI}=[0.00,0.13]$. As in Study 1, simple main effect analyses showed that included participants expressed higher hiring intentions when a strong vita was available $(M=3.00, S D=0.65)$ compared to a weak vita $(M=2.31, S D=0.62), F$ $(1,102)=17.00, p<.001, \eta^{2}=.14,95 \% \mathrm{CI}=[0.04,0.27]$. In contrast, excluded participants showed similar hiring intentions regardless of a strong $(M=2.78, S D=0.55)$ or weak vita $(M=2.57$, $S D=0.59), F(1,102)=1.74, p=.190$, see Figure 2 .

\section{Discussion}

Participants who faced inclusion expressed higher hiring intentions when they viewed a strong vita of a job candidate than when they viewed a weak vita; in contrast, participants who faced exclusion indicated similar hiring intentions of the job candidate regardless of the vita's quality. Hence, the results revealed that social exclusion leads people to undifferentiatedly adopt persuasive messages. These findings point to the cognitive deficits socially excluded individuals have to face (Baumeister 


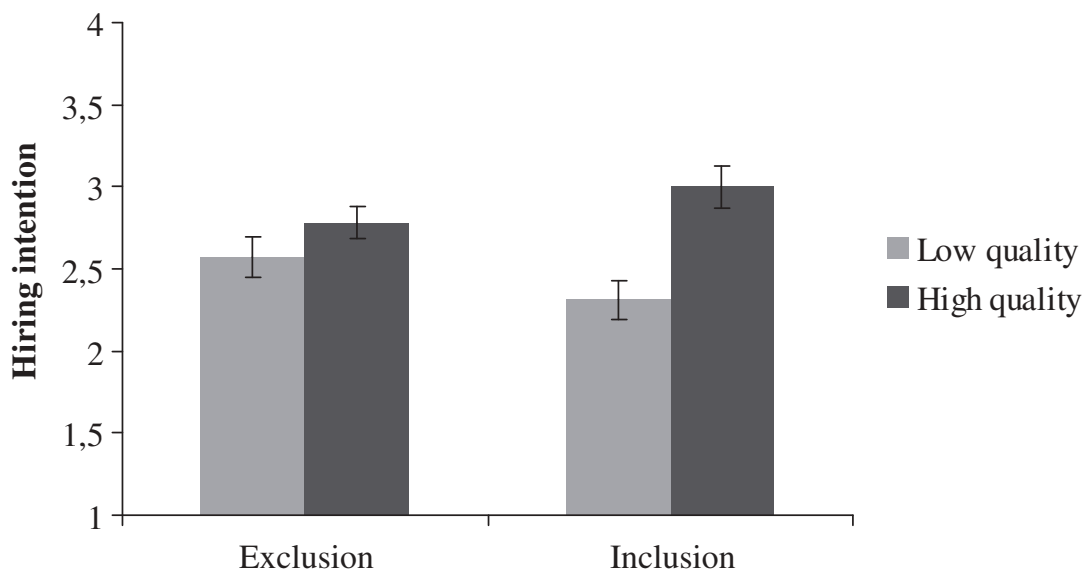

Figure 2. The effect of inclusionary status $\times$ persuasion quality on hiring intention (Study 2); error bars represent $\pm 1 S E$.

et al., 2005; Baumeister et al., 2002; Twenge et al., 2003) that may lead to a lower ability to process information. Using different manipulations, Study 2 replicated the results of Study 1 with stronger effects. In Study 3, we intended to examine a possible boundary condition.

\section{Study 3}

The previous studies showed that social exclusion affects the success of persuasive attempts leading people to undifferentiatedly adopt attitudes. In the last study, we aimed to replicate this finding and, moreover, explore a possible boundary condition. Research has revealed that processing of persuasive messages is biased on source credibility (Pornpitakpan, 2004): In particular, people who lack motivation for systematic processing are often influenced by the heuristic that credible communicators' assertions are valid (e.g., Chaiken \& Maheswaran, 1994). This mental shortcut requires less effort and is therefore particularly suitable for conditions of low-level processing, such as after social exclusion. Thus, we assumed that the result pattern observed in the previous two studies would particularly hold for reliable situations-that is, situations including a credible communicator. Analogues to the findings by Baumeister et al. (2005), we moreover suggested that excluded people break out of their low-level functioning and process all relevant information similar to included people under conditions of low reliability, when the need for a more elaborate processing may be recognized. To investigate these assumptions, we varied the manipulations of inclusionary status and persuasion quality: We manipulated exclusion vs. inclusion using an essay task (e.g., Maner, DeWall, Baumeister, \& Schaller, 2007) and persuasion quality using a proposal that argued in favor of implementing a sustainability label including low- vs. high-quality arguments. Moreover, we manipulated source credibility by presenting a non-qualified celebrity vs. an expert-looking unknown person as communicator. We hypothesized that, under a credible communicator, excluded participants would adopt persuasive messages regardless of argument quality, whereas included participants would be more persuaded by high- compared to low-argument quality. Further, we predicted that, under a non-credible communicator, excluded participants would be more persuaded by high- compared to low-quality arguments similar to included participants. 


\section{Method}

\section{Participants and design}

Participants were 157 students who volunteered for research credit. As we had failed to give instructions to explicitly consider the photo of the communicator, we only included those participants into the final sample who checked yes at the question of whether they had noticed the photo to ensure sufficient impact of our manipulation. This resulted in a sample of 112 participants (87 female and 25 male; age: $M=21.37, S D=5.51)$.

The experiment was based on a 2 (inclusionary status: exclusion vs. inclusion) $\times 2$ (persuasion quality: low vs. high) $\times 2$ (source credibility: low vs. high) between-subject design with random assignment to conditions.

\section{Procedure and materials}

After handing over the paper-and-pencil questionnaire, participants indicated their consent and read a short text informing them that the following study would investigate the relationship between mental visualization, personality traits, and attitudes. Then, they were asked to remember vividly and write about a previous experience from their lives that has been shown to evoke comparable responses to those using interpersonal methods for creating exclusion (Maner et al., 2007; Pickett, Gardner, \& Knowles, 2004). Participants were either asked to write about a time they had been excluded from one or more others (exclusion condition). Or they were instructed to write about a time they had been included and accepted from one or more others (inclusion condition). After that, they completed a manipulation check. Subsequently, they were instructed to read an excerpt from a speech that was allegedly delivered at the "UN sustainability conference." The speech included a proposal about implementing a sustainability label. This proposal was either presented with weak (low-quality condition) arguments (e.g., the label is popular and image promoting) or with strong (high-quality condition) arguments (e.g., the label protects the environment and creates good working conditions in third-world countries). The excerpt from the speech was accompanied by a photo of the alleged speaker behind the famous lectern of the UN. The photo either depicted a famous celebrity, Leondardo DiCaprio, (low-credibility condition) or an unknown man referred to "John Wetherand" (high credibility condition); both speakers had similar clothing and age ${ }^{1}$. Participants then indicated their attitudes toward the speech's proposal and filled out manipulation checks on persuasion quality and source. In the end, participants were thanked and debriefed.

\section{Manipulation check (inclusionary status)}

As in Study 2, participants responded to 20 items on need fulfilment using $1=$ not at all to $5=$ very much response scales $(\alpha=.97$; based on Jamieson et al., 2010).

\section{Implementing intention}

As in Pierro, Mannetti, Kruglanski, Klein, and Orehek (2012), participants completed seven items on their attitudes toward implementing the sustainability label. In the first item, they indicated their agreement on a $1=$ not at all to $7=$ very much response scale. The other six items contained semantic differentials ranging from 1 to 7: "bad"- "good", "damaging"- "advantageous", "foolish"- "wise", "useless"— "useful", "unproductive"— "productive" and "inopportune"- "opportune". All items were combined to an overall index $(\alpha=.88)$.

\section{Manipulation check (persuasion quality)}

Participants answered the following question: "How convincing did you experience the arguments?" on a $1=$ not very convincing to $5=$ very convincing response scale. 
Manipulation check (source credibility)

At the end, participants were asked whether or not they had noticed the photo of the speaker.

\section{Results}

\section{Manipulation checks}

To check the impact of the inclusionary status manipulation, a t-test was conducted on the manipulation check of inclusionary status. Excluded participants indicated significantly less need fulfilment $(M=1.95, S D=0.61)$ than included participants $(M=4.26, S D=0.51), t(110)=21.66$, $p<.001, d=4.09,95 \% \mathrm{CI}=[3.43,4.75]$. To check the impact of the persuasion-quality manipulation, we further conducted a 2 (inclusionary status) $\times 2$ (persuasion quality) $\times 2$ (source credibility) ANOVA on the manipulation check of persuasion quality. A marginally significant main effect of persuasion quality, $F(1,97)=3.28, p=.073, \eta^{2}=.03,95 \% \mathrm{CI}=[0.00,0.13]$, but no other effects emerged, $p s>.217$. Participants in the low-quality condition reported the arguments to be marginally significantly less convincing $(M=3.24, S D=0.99)$ than participants in the high quality condition $(M=3.55, S D=0.78)$.

\section{Implementing intention}

A 2 (inclusionary status) $\times 2$ (persuasion quality) $\times 2$ (source credibility) ANOVA on the implementing intention revealed a significant main effect of persuasion quality, $F(1,104)=7.61, p=.007$, $\eta^{2}=.07,95 \% \mathrm{CI}=[0.01,0.18]$. Participants who were presented the weak speech expressed a lower intention to implement the label $(M=5.09, S D=1.15)$ than participants who were presented the strong speech $(M=5.55, S D=0.83)$. No significant other main effects or 2-way interactions emerged, $p s>.101$. Notably, however, the ANOVA showed a significant 3-way interaction, $F(1,104)=4.31, p=.040, \eta^{2}=.04,95 \% \mathrm{CI}=[0.00,0.13]$. To probe this interaction, we analyzed the effect of inclusionary status $\times$ persuasion quality at the conditions of low- versus high-source credibility. These analyses replicated the result pattern observed in Studies 1 and 2 only in the high source credibility condition: In this condition, the 2 (inclusionary status) $\times 2$ (persuasion quality) ANOVA showed no main effect of inclusionary status, $F(1,41)=2.56, p=.117$, but a marginally significant main effect of persuasion quality emerged, $F(1,41)=3.97, p=.053, \eta^{2}=.09,95 \%$ $\mathrm{CI}=[0.00,0.27]$. Importantly, the ANOVA also indicated a significant interaction, $F(1,41)=5.82$, $p=.020, \eta^{2}=.12,95 \% \mathrm{CI}=[0.002,0.31]$. As in the previous studies, simple main effect analyses showed that included participants indicated higher implementing intentions when they read a strong speech $(M=5.84, S D=0.62)$ compared to a weak speech $(M=4.71, S D=1.22)$ from John Wetherand, $F(1,104)=6.92, p=.010, \eta^{2}=.06,95 \% \mathrm{CI}=[0.00,0.17]$, whereas excluded participants expressed similar implementing intentions regardless of a strong $(M=5.63, S D=0.83)$ or a weak speech $(M=5.74, S D=0.62)$ from John Wetherand, $F(1,104)=0.07, p=.795$. In the low-source credibility condition, on the other hand, the 2 (inclusionary status) $\times 2$ (persuasion quality) ANOVA only revealed a significant main effect of persuasion quality, $F(1,63)=4.41, p=.040, \eta^{2}=.07,95 \%$ $\mathrm{CI}=[0.00,0.20]$, but no other effects, $p s>.498$. Simple main effect analyses showed that excluded participants who faced the non-credible communicator now differed in their intentions depending on argument quality: They reported higher intentions to implement the label when reading strong $(M=5.48, S D=0.94)$ compared to weak arguments $(M=4.75, S D=1.17)$ from Leonardo DiCaprio, $F(1,104)=4.45, p=.037, \eta^{2}=.04,95 \% \mathrm{CI}=[0.00,0.14]$, see Figure 3.

\section{Discussion}

Study 3 replicated the findings of the previous two studies, but only when the situation had a reliable character: When a credible source, an expert-looking man, communicated the message, excluded 


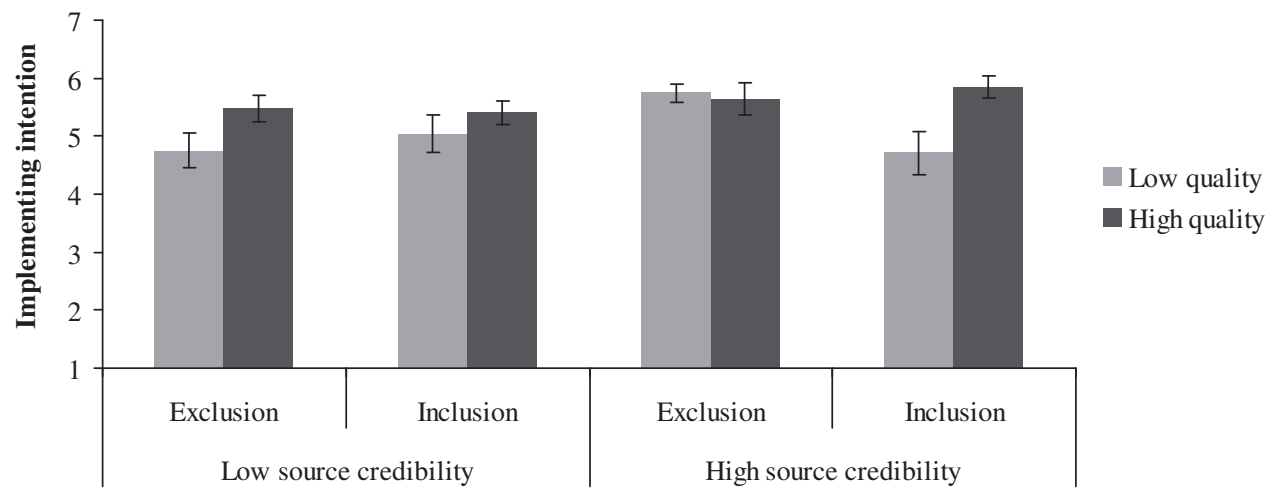

Figure 3. The effect of inclusionary status $\times$ persuasion quality $\times$ source credibility on implementing intention (Study 3 ); error bars represent $\pm 1 S E$.

participants did not differ between strong and weak arguments in comparison to included participants. However, when the communicator was non-credible, a non-qualified celebrity, excluded participants were more persuaded by strong than by weak arguments.

Two important aspects emerge from these results: First, in their reduced processing of persuasive messages, excluded people seem to rely on simple cues or heuristics. Source credibility might only be one facet of this relatively simple processing; a larger number of communicators (Harkins \& Petty, 1981) or arguments (Petty \& Cacioppo, 1984) may lead to similar results. Second, excluded people are not fixed in their low processing mode. Our findings point out that they switch to a more elaborated processing when the situation signals unreliability. A similar finding has been observed with regard to self-regulation: Decrements in self-regulation after social exclusion can be eliminated under specific circumstances, but socially excluded people are normally disinclined to make this effort (Baumeister et al., 2005).

In Study 3, we replicated and extended the findings of Studies 1 and 2 using different manipulations and demonstrated that social exclusion can affect the success of persuasive attempts. However, it should be noted that our manipulation check of persuasion quality only revealed a marginal result. This might be due to the fact that both speeches were written in a sophisticated way. Due to the significant main effect of persuasion quality on our main dependent variable, we nevertheless feel confident that participants perceived a quality difference between both speeches.

\section{General discussion}

The reported studies provide convergent evidence that social exclusion affects the success of persuasive attempts. Studies 1 and 2 demonstrated that participants adopted persuasive messages regardless of argument quality when they were socially excluded; this undifferentiated response was not shown by socially included participants who were more persuaded by high- compared to lowquality arguments. In Study 3, we observed that this pattern could only be replicated in reliable situations - that is, when the communicator appeared credible. These findings emerged using three different manipulations of social exclusion and persuasion.

As social exclusion is usually followed by cognitive deficits (Baumeister et al., 2005; Baumeister et al., 2002; Twenge et al., 2003), we suggest that people under social exclusion are more likely to adopt persuasive messages in an undifferentiated way because they are unable or unmotivated to process all relevant information (Petty, 2013; Petty \& Cacioppo, 1981). Similarly, past research has indicated that socially excluded people are more susceptible to persuasive attempts (Carter-Sowell et al., 2008; DeWall, 2010; Riva et al., 2014; Williams et al., 2000), particularly when they are trying to address their need to belong (Williams et al., 2010). However, our set of studies differs in two 
important ways from this research: First, excluded individuals were not generally more persuaded than included individuals (but instead became persuaded regardless of argument quality). Second, no social cue was available in our studies, because neither purchasing a razor nor hiring a job candidate nor implementing a label gave the participants the possibility to re-include or affiliate themselves. We therefore assume that, without offering a social incentive, excluded people are not more influenced by persuasion per se but instead adopt persuasive messages more undifferentiatedly due to their unwillingness to scrutinize all available information.

Investigating boundary conditions, we moreover found that this undifferentiated response pattern was eliminated when the situation appeared unreliable. This ability of excluded people to control cognitive processes if necessary has already been observed in other research: When offering a cash incentive or increasing self-awareness, decrements in self-regulation decreased in socially excluded people (Baumeister et al., 2005). Interestingly, high source credibility appeared to be the default state in our studies: Participants in Studies 1 and 2 seemed to have taken the situations' reliability for granted, and in Study 3, source credibility was only eliminated by a strong negative cue. Therefore, it could be argued that excluded people have to be actively shaken into action when cognitive decrements need to be overcome. Source credibility was revealed to be a critical factor in the tendency to undifferentiatedly adopt persuasive messages after social exclusion. According to ELM, source credibility is one of many peripheral cues that are particularly effective in reduced elaboration settings (Petty, 2013; Petty \& Cacioppo, 1981). We suppose that other peripheral cues, like a larger number of communicators (Harkins \& Petty, 1981) or arguments (Petty \& Cacioppo, 1984) might be equally effective in situations of social exclusion, as they can serve as mental shortcuts for processing new information when people are cognitively limited.

There are some limitations that should be mentioned: First, in their undifferentiated response to persuasion, we assumed the underlying mechanism in socially excluded people to be their cognitive deficits that reduce their willingness to scrutinize all available information. Although previous research supports this conclusion, our results did not specify this mechanism of action. Future studies investigating the underlying process would move us toward a better understanding of the found pattern. Second, examining further boundary conditions, particularly with regard to peripheral cues, should receive more attention in future research. Third, the comparison condition in our studies represented social inclusion and not a neutral state. As assumed by the sociometer theory (Leary, 1999), humans usually experience inclusion as the default state, which is in line with empirical research demonstrating no significant differences between social inclusion and neutral control conditions (Baumeister et al., 2005; Twenge et al., 2001). Therefore, we would expect a replication of our findings when using a neutral control condition.

Our results showed that, under certain conditions, social exclusion can lead people to undifferentiatedly adopt persuasive messages. These findings are particularly important in circumstances in which persuasion is playing a major role-for example, within promotional and advertising contexts. People suffering under exclusion, situationally or chronically, might be especially prone to make wrong decisions by adopting attitudes regardless of content. To overcome this maladaptive pattern, important messages should be viewed from different angles to be able to activate a more elaborate processing mode.

\section{Note}

1. To ensure that the appearance of both speakers alone was associated with different credibility levels, we conducted a pre-test. Nineteen participants rated on four items for each speaker how knowledgeable, qualified, competent, and sufficiently expert the speaker is to make serious recommendations about sustainability (based on Pierro et al., 2012) on $1=$ not at all to $7=$ very much response scales $(\alpha=.91-.93)$. Leonardo DiCaprio was experienced as significantly less credible $(M=3.58, S D=1.28)$ than John Wetherand $(M=5.55, S D=0.92)$, $t(18)=-5.57, p<.001, d=1.81,95 \% \mathrm{CI}=[0.93,2.66]$. 


\section{Acknowledgment}

The authors wish to thank Sarah Danböck, Katharina Ritschel, Clara Sowade, Friedemann Starke, Sara Volkmer, and Regina Wendlinger for assistance during data collection.

\section{Notes on contributors}

Michaela Pfundmair is a Professor at the University of Munich. Her main research focuses on the causes and consequences of social exclusion. Nilüfer Aydin is a Professor at the University of Klagenfurt. Her research involves social exclusion at the individual and group level. Dieter Frey is an Emeritus Professor at the University of Munich. Inter alia, his research investigates decision-making behavior, team work, leadership, and systems of values.

\section{References}

Aydin, N., Fischer, P., \& Frey, D. (2010). Turning to god in the face of exclusion: Effects of social exclusion on religiousness. Personality and Social Psychology Bulletin, 36, 742-753.

Baumeister, R. F., DeWall, C. N., Ciarocco, N. J., \& Twenge, J. M. (2005). Social exclusion impairs self-regulation. Journal of Personality and Social Psychology, 88, 589-604.

Baumeister, R. F., \& Heatherton, T. F. (1996). Self-regulation failure: An overview. Psychological Inquiry, 7, 1-15.

Baumeister, R. F., \& Leary, M. R. (1995). The need to belong: Desire for interpersonal attachments as a fundamental human motivation. Psychological Bulletin, 117, 497-529.

Baumeister, R. F., Twenge, J. M., \& Nuss, C. K. (2002). Effects of social exclusion on cognitive processes: Anticipated aloneness reduces intelligent thought. Journal of Personality and Social Psychology, 83, 817-827.

Bernstein, M. J., \& Claypool, H. M. (2012a). Not all social exclusions are created equal: Emotional distress following social exclusion is moderated by exclusion paradigm. Social Influence, 7, 113-130.

Bernstein, M. J., \& Claypool, H. M. (2012b). Social exclusion and pain sensitivity: Why exclusion sometimes hurts and sometimes numbs. Personality and Social Psychology Bulletin, 38, 185-196.

Briñol, P., Petty, R. E., \& Stavraki, M. (2012). Power increases the reliance on first-impression thoughts. Revista De Psicología Social, 27, 293-303.

Carter-Sowell, A. R., Chen, Z., \& Williams, K. D. (2008). Ostracism increases social susceptibility. Social Influence, 3, 143-153.

Chaiken, S., \& Maheswaran, D. (1994). Heuristic processing can bias systematic processing: Effects of source credibility, argument ambiguity, and task importance on attitude judgment. Journal of Personality and Social Psychology, 66, 460-473.

Cialdini, R. B., Vincent, J. E., Lewis, S. K., Catalan, J., Wheeler, D., \& Darby, B. L. (1975). Reciprocal concessions procedure for inducing compliance: The door-in-the-face technique. Journal of Personality and Social Psychology, 31, 206-215.

Costa, P. T., Jr., \& McCrae, R. R. (1992). Revised NEO Personality Inventory (NEO-PI-R) and NEO Five-Factor Inventory (NEO-FFI) professional manual. Odessa, FL: Psychological Assessment Resources.

DeWall, C. N. (2010). Forming a basis for acceptance: Excluded people form attitudes to agree with potential affiliates. Social Influence, 5, 245-260.

Eisenberger, N. I., Lieberman, M. D., \& Williams, K. D. (2003). Does exclusion hurt? An fMRI study of social exclusion. Science, 302, 290-292.

Fiske, S. T., \& Yamamoto, M. (2005). Coping with exclusion. Core social motives across cultures. In K. D. Williams, J. P. Forgas, \& W. Von Hippel (Eds.), The social outcast: Exclusion, social exclusion, exclusion, and bullying (pp. 185-198). New York, NY: Psychology Press.

Harkins, S. G., \& Petty, R. E. (1981). Effects of source magnification of cognitive effort on attitudes: An information processing view. Journal of Personality and Social Psychology, 40, 401-413.

Hitlan, R. T., Kelly, K. M., Shepman, S., Schneider, K. T., \& Zaraté, M. A. (2006). Language exclusion and the consequences of perceived exclusion in the workplace. Group Dynamics: Theory, Research, and Practice, 10, 56-70.

Jamieson, J. P., Harkins, S. G., \& Williams, K. D. (2010). Need threat can motivate performance after ostracism. Personality and Social Psychology Bulletin, 36, 690-702.

Janssen, L., Fennis, B. M., Pruyn, A. T. H., \& Vohs, K. D. (2008). The path of least resistance: Regulatory resource depletion and the effectiveness of social influence techniques. Journal of Business Research, 61, 1041-1045.

Kerr, G. F., Beede, P., Proud, W., \& Schultz, D. (2010). The elaboration likelihood model in the new millennium: An exploration study. American Academy of Advertising European conference, Milan, Italy.

Leary, M. R. (1999). Making sense of self-esteem. Current Directions in Psychological Science, 8, 32-35.

Maner, J. K., DeWall, N., Baumeister, R. F., \& Schaller, M. (2007). Does social exclusion motivate interpersonal reconnection? Resolving the "porcupine problem." Journal of Personality and Social Psychology, 92, 42-55. 
Petty, R. E. (2013). Two routes to persuasion: State of the art. International Perspectives on Psychological Science, 2 , 229-247.

Petty, R. E., \& Cacioppo, J. T. (1981). Attitudes and persuasion: Classic and contemporary approaches. Dubuque, IA: Brown.

Petty, R. E., \& Cacioppo, J. T. (1984). The effects of involvement on responses to argument quantity and quality: Central and peripheral routes to persuasion. Journal of Personality and Social Psychology, 46, 69-81.

Petty, R. E., Cacioppo, J. T., \& Schumann, D. (1983). Central and peripheral routes to advertising effectiveness: The moderating role of involvement. Journal of Consumer Research, 10, 135-146.

Petty, R. E., Wells, G. L., \& Brock, T. C. (1976). Distraction can enhance or reduce yielding to propaganda: Thought disruption versus effort justification. Journal of Personality and Social Psychology, 34, 874-884.

Pfundmair, M., Lermer, E., Frey, D., \& Aydin, N. (2015). Construal level and social exclusion: Concrete thinking impedes recovery from social exclusion. The Journal of Social Psychology, 155, 338-355.

Pickett, C. L., Gardner, W. L., \& Knowles, M. (2004). Getting a cue: The need to belong and enhanced sensitivity to social cues. Personality and Social Psychology Bulletin, 30, 1095-1107.

Pierro, A., Mannetti, L., Kruglanski, A. W., Klein, K., \& Orehek, E. (2012). Persistence of attitude change and attitudebehavior correspondence based on extensive processing of source information. European Journal of Social Psychology, 42, 103-111.

Pornpitakpan, C. (2004). The persuasiveness of source credibility: A critical review of five decades' evidence. Journal of Applied Social Psychology, 34, 243-281.

Riva, P., Williams, K. D., Torstrick, A. M., \& Montali, L. (2014). Orders to shoot (a camera): Effects of ostracism on obedience. The Journal of Social Psychology, 154, 208-216.

Twenge, J. M., Baumeister, R. F., Tice, D. M., \& Stucke, T. S. (2001). If you can't join them, beat them: Effects of social exclusion on aggressive behavior. Journal of Personality and Social Psychology, 81, 1058-1069.

Twenge, J. M., Catanese, K. R., \& Baumeister, R. F. (2003). Social exclusion and the deconstructed state: Time perception, meaninglessness, lethargy, lack of emotion, and self-awareness. Journal of Personality and Social Psychology, 85, 409-423.

Wegener, D. T., Petty, R. E., Smoak, N. D., \& Fabrigar, L. R. (2004). Multiple routes to resisting attitude change. In E. S. Knowles, \& J. A. Linn (Eds.), Resistance and Persuasion (pp. 13-38). Mahwah, NJ: Erlbaum.

Williams, K. D. (2009). Ostracism: A temporal need-threat model. Advances in Experimental Social Psychology, 41, 275-314.

Williams, K. D., Chen, Z., \& Wegener, D. (2010). Persuasion after ostracism: Need-based influences on persuasion. In J. P. Forgas, J. Cooper, \& W. D. Crano (Eds.), The psychology of attitudes and attitude change (pp. 199-214). New York, NY: Psychology Press.

Williams, K. D., Cheung, C. K., \& Choi, W. (2000). Cyberostracism: Effects of being ignored over the Internet. Journal of Personality and Social Psychology, 79, 748-762.

Zuwerink, J. R., \& Devine, P. G. (1996). Attitude importance and resistance to persuasion: It's not just the thought that counts. Journal of Personality and Social Psychology, 70, 931-944. 